This item was submitted to Loughborough's Research Repository by the author.

Items in Figshare are protected by copyright, with all rights reserved, unless otherwise indicated.

\title{
Effect of bed temperature and infra-red lamp power on the mechanical properties of parts produced using high-speed sintering
}

PLEASE CITE THE PUBLISHED VERSION

PUBLISHER

(C) Taylor \& Francis

LICENCE

CC BY-NC-ND 4.0

\section{REPOSITORY RECORD}

Majewski, Candice E., B.S. Hobbs, and Neil Hopkinson. 2019. "Effect of Bed Temperature and Infra-red Lamp Power on the Mechanical Properties of Parts Produced Using High-speed Sintering". figshare. https://hdl.handle.net/2134/3499. 
This item was submitted to Loughborough's Institutional Repository by the author and is made available under the following Creative Commons Licence conditions.

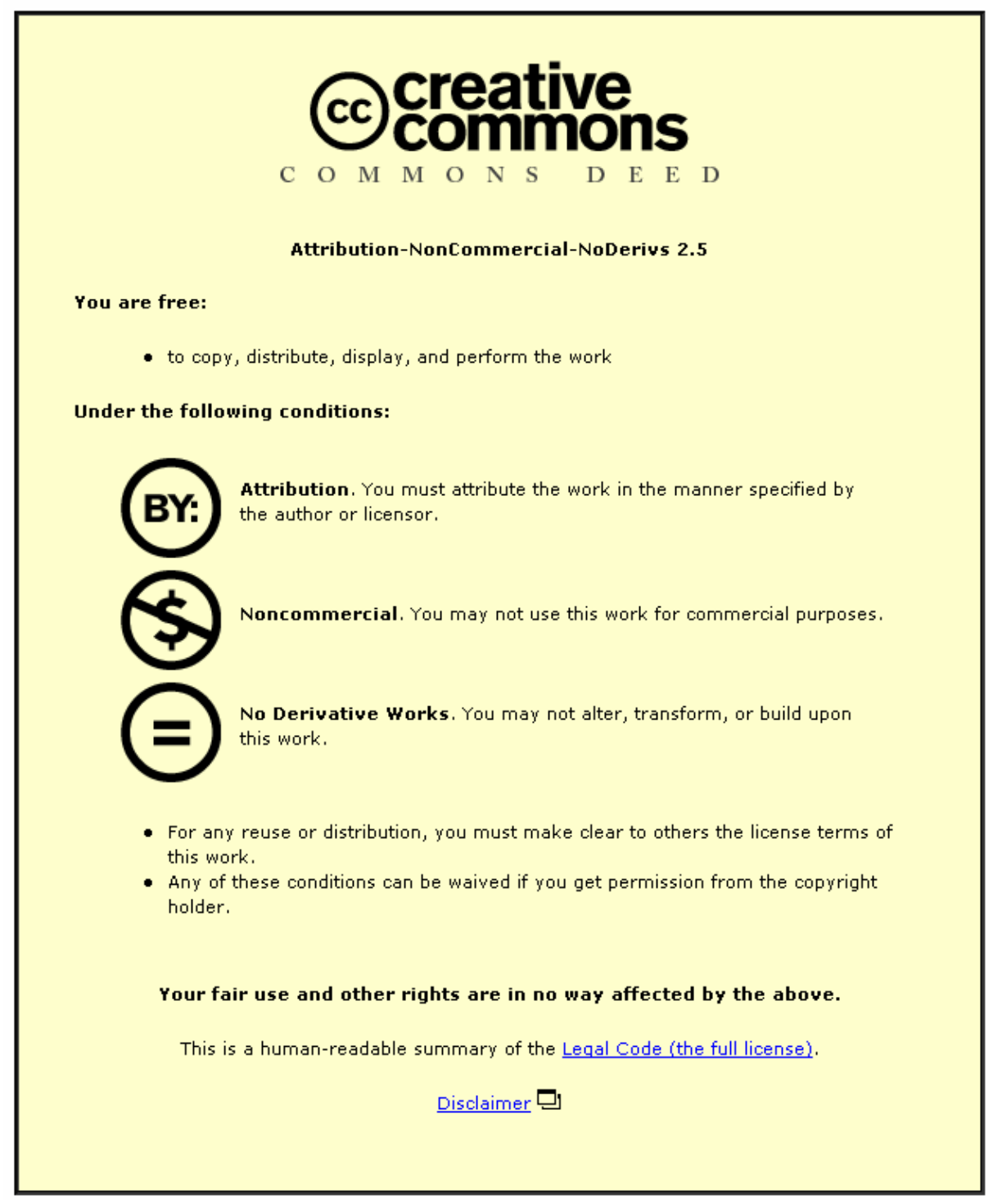

For the full text of this licence, please go to: http://creativecommons.org/licenses/by-nc-nd/2.5/ 
Effect of bed temperature and infra-red lamp power on the mechanical properties of parts produced using High Speed Sintering

\section{C.E.MAJEWSKI*, B.S.HOBBS, N.HOPKINSON}

\section{Loughborough University, UK}

\section{Abstract}

High Speed Sintering is a new, layer-based, manufacturing process, based on printing consecutive cross-sections with a radiation-absorbing material, and exposing to an infra-red lamp, in order to initiate sintering of polymer powder particles in the appropriate profile.

Research was carried out to determine the effects of varying process parameters on the mechanical properties of parts produced using this process. Results showed that increasing the temperature of the part bed led to an increase in the mechanical properties of the parts produced, and that increasing the infra-red lamp power had the same effect, but to a lesser degree. It was also found that these increases in process parameters led to a corresponding increase in the hardness of the unsintered powder, which could lead to difficulties with post-process powder removal.

Keywords: Rapid Prototyping, Rapid Manufacturing, High Speed Sintering, infra-red power, part bed temperature, mechanical properties 


\section{Introduction}

\section{Rapid Prototyping}

Rapid Prototyping (RP) is the name given to a group of related technologies which can be generally defined as the layer by layer fabrication of threedimensional models directly from a computer-aided design (CAD) ${ }^{1}$. Rather than using traditional subtractive (e.g. machining) or formative (e.g. injection moulding) methods, RP relies on the discrete slicing of a CAD model, which is then built up in layers from a base material (often a powder or a resin), finally producing a full 3-dimensional part.

$\mathrm{RP}$ has been shown to have many associated benefits, including the production of complex internal and external geometries, the elimination of the requirement for tooling, and reductions in waste material.

\section{Rapid Manufacturing}

Whilst the technologies were originally thought of as prototyping methods, in recent years there has been increasing interest in using these technologies, and their associated benefits, to produce end-use components, coining the term 'Rapid Manufacturing' (RM)².

Several niche uses of RM (e.g. for customised hearing aids, and components in Formula 1 cars $^{3}$ ) have used existing RP machines to produce end-use 
products. Whilst these applications have had some success, there are many limitations with the use of RP machines for RM, and it can be said that the recent growth of RM applications has occurred in spite of, rather than because of, the RP machines themselves. Further work is therefore required in order for RM to become widespread and competitive, and will require system manufacturers to focus on new sets of user requirements, including reduction of machine and material costs, and improvements to accuracy, resolution and the mechanical properties of parts produced. Increased throughput will also be required in order to allow competitiveness with conventional manufacturing methods.

\section{High Speed Sintering}

High Speed Sintering is a new, powder-based, layer manufacturing process, developed at Loughborough University ${ }^{4,5}$, and was developed with the specific intention of being used for RM. The process retains the major benefits of RP technologies (internal geometries, part complexity, manufacture of multiple

free-moving assemblies as one ${ }^{6}$ ), whilst eliminating some of the major drawbacks, specifically machine costs and process speed. It will be possible to fabricate much larger scale components than can be produced using current RP technologies, and it is expected that it will be competitive with injection moulding, particularly in terms of throughput.

The process has similarities with Selective Laser Sintering (SLS), in that it sinters the required cross-sectional area of subsequent layers of powder in 
order to create the final part. At present the machine used is a modified DTM Sinterstation $2500 \mathrm{Cl}$, and the powder used is Duraform PA (Nylon 12).

The major difference between SLS and HSS is in the mechanism by which sintering is initiated. Whereas the SLS process uses a laser to sinter the cross-sectional profile, in HSS a Xaar printhead deposits a Radiation Absorbing Material (RAM) over the appropriate area and a $2 \mathrm{~kW}$ infra-red lamp is then passed across the entire build area (see Figure 1).

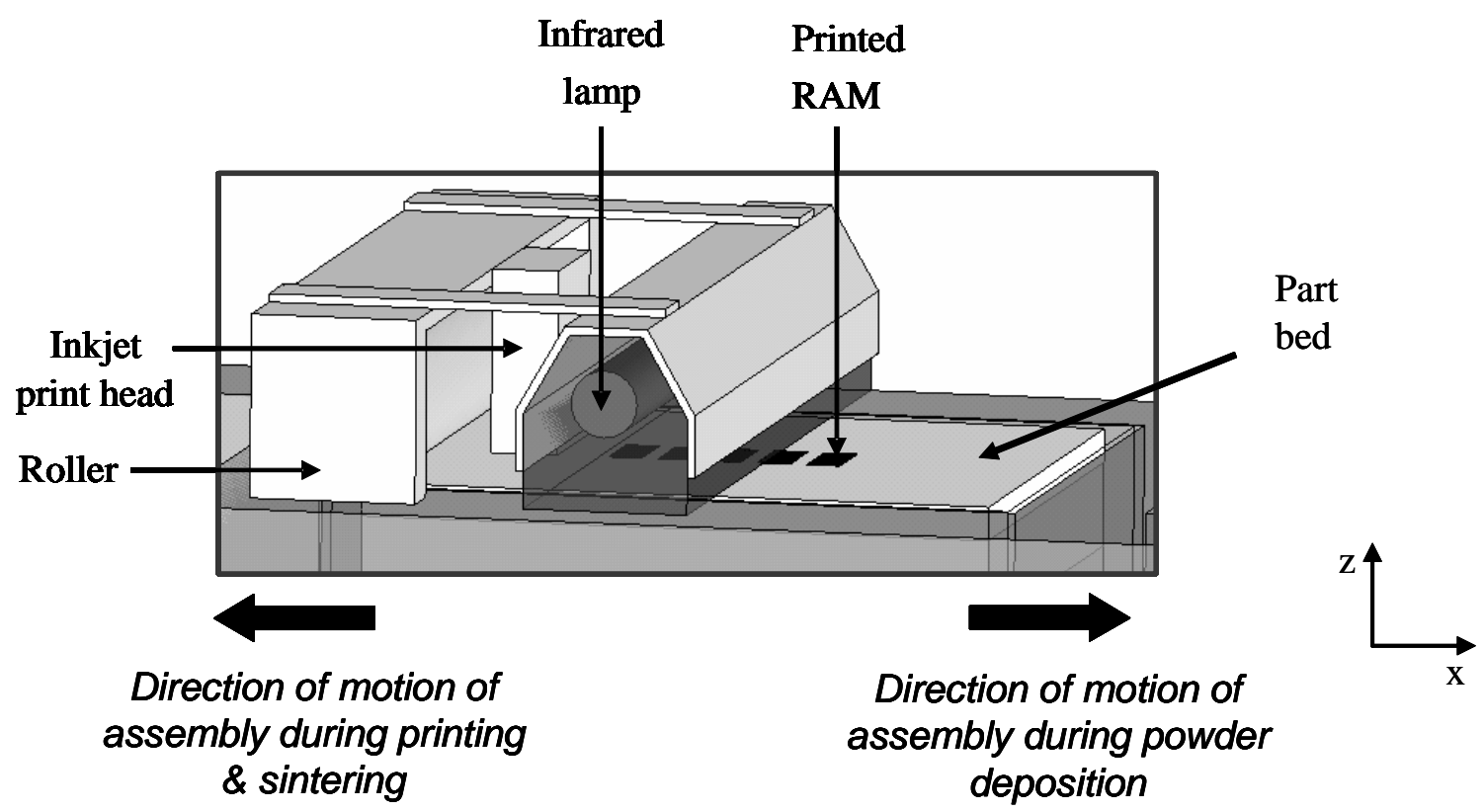

Figure 1 - HSS machine set-up

Given the selection of an appropriate RAM for the powder used, areas in which the powder is printed by the RAM will absorb sufficient energy to elevate the temperature of the underlying powder to its melt point, allowing sintering to take place. Areas not printed with the RAM will absorb less 
energy, therefore not exceeding their melt point and not becoming sintered. The un-sintered powder can be removed from the part upon completion of the build.

The HSS process can be separated into several discrete steps:

- Standard CAD software is used to produce the CAD model of a part

- The CAD model is then sliced into discrete cross-sections, represented as bitmap images, and transferred to the HSS machine

- The powder bed and feed chambers are subjected to a warm-up cycle

- Powder is deposited via a roller system onto the build area

- RAM is deposited over the required cross-sectional area via the inkjet print head

- Following the printing of the area, an infra-red lamp is passed over the entire build area, sintering the areas of powder on which the RAM has been deposited

- Subsequent layers of powder are deposited onto the build area, and the process is repeated

- The machine is left to cool before part removal

- Unsintered powder is removed from the parts

\section{RP/M Part Properties}

For RP applications, the mechanical properties of the parts produced are often of low importance, as parts are intended simply for visualisation 
purposes, or undemanding, short-term, form, fit and function testing. As the move towards RM continues, with the production of functional, end-use components, the life-time and mechanical properties of parts will become increasingly important. This has already been recognised in work investigating the mechanical properties and aging effects of some currently available RP materials ${ }^{7,8}$, and on the effects of processing parameters on the properties of parts produced ${ }^{9,10,11}$.

As HSS is currently still in the development stage, little is known about the effects of the process parameters on the properties of the parts produced, and in order for the process to become widely accepted and used, these issues must be addressed. The work presented here therefore focussed on identifying the effects of some of the key process parameters on part properties.

There are various similarities between HSS and SLS, specifically that both processes involve the sintering of a polymer powder. Various research has been carried out investigating the effect of changing process variables on the properties of SLS parts, and it was felt that some of the results presented for this process would give an indication of which parameters would be important for HSS. 
Within the SLS process, sintering of the polymer powder in the required areas is initiated with the use of a CO2 laser. Various studies ${ }^{10,12}$ have shown that increasing the laser power leads to an increase in mechanical properties (e.g. elongation at break and tensile strength) of an SLS part. It was considered likely that this principle would also hold true for the HSS process, whereby an increase in the power emitted by the infra-red lamp would also correspond to an increase in the part properties. The effect of varying the lamp power was therefore chosen as a factor for this research.

\section{Part Bed Temperature}

It has been previously established that the temperature of the powder bed in the SLS process also affects the mechanical properties of the parts produced, whereby an increase in the temperature leads to an increase in part density ${ }^{13}$ and therefore to an increase in mechanical properties ${ }^{12,14,15}$. Due to the similarities between the SLS and HSS processes, it was felt that this was also likely to be the case for HSS, and the effect of varying the part bed temperature was also included for investigation.

\section{Methodology}


In order to test the tensile strength, Young's Modulus, and elongation at break of parts produced using the HSS process, a series of 'dogbone' type specimens were produced (see Figure 2) under different sets of operating conditions. All specimens were produced in accordance with ASTM D638-96 (Standard Test Methods for Tensile Properties of Plastics) ${ }^{16}$.

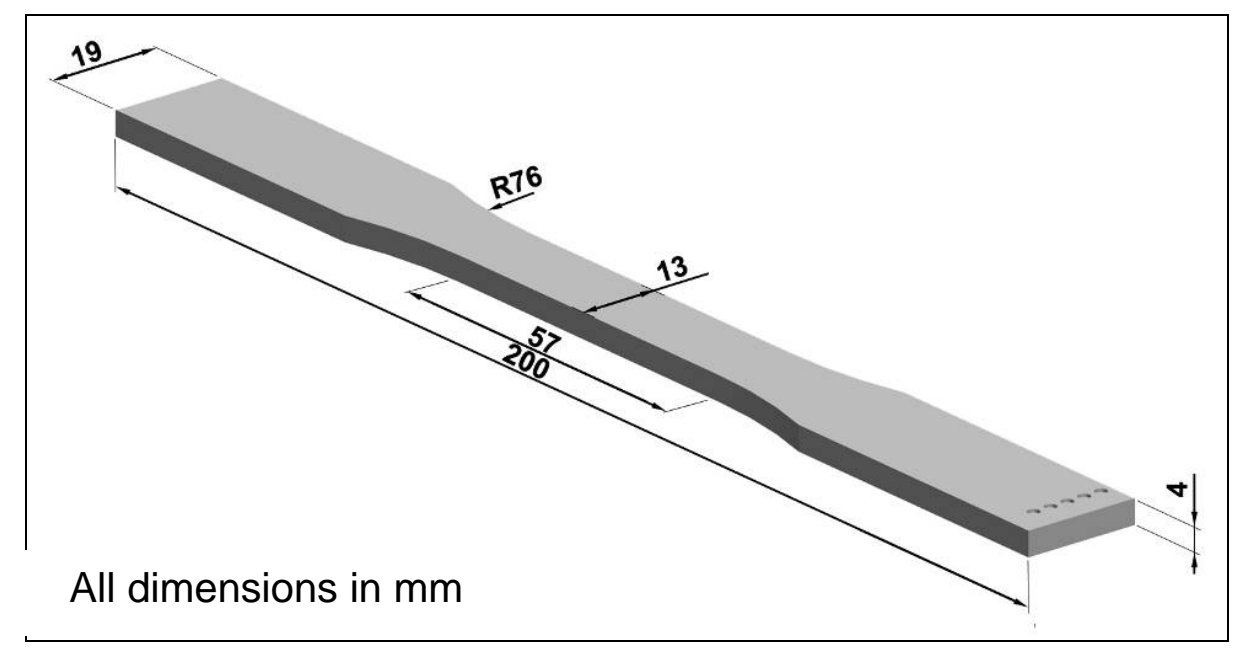

Figure 2 - Tensile test specimen

For each set of operating conditions, six specimens were produced, in three layers of two parts, to minimise any variance in the results. Figure 3 shows the positioning of the specimens within the build area. 


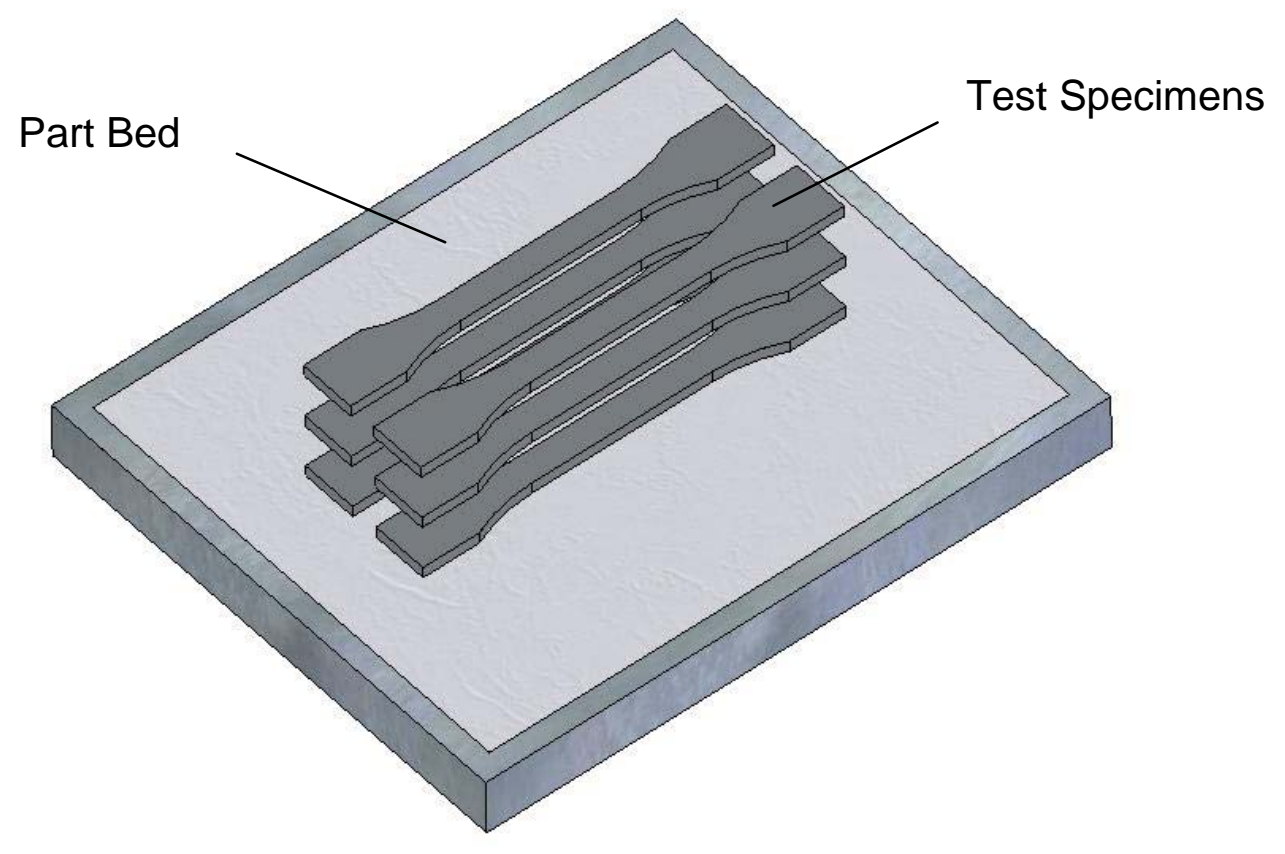

Figure 3 - Positioning and orientation of test specimens

\section{Build parameters}

The tensile test specimens were built using a nylon 12 powder, Duraform ${ }^{\circledR}$ PA, and were all produced from the same batch of powder, in order to prevent any variations in mechanical properties caused by differences in powder history. This has previously been shown to have an effect in the SLS process $^{17}$, and it was therefore considered important to eliminate any possibility of similar effects in this case.

As mentioned previously, the current HSS process involves a warm-up cycle to allow the powder in the feed chamber to warm sufficiently prior to deposition, and to allow the powder in the part chamber to reach an elevated 
temperature, in order that less input power is required to initiate sintering than if room temperature powder is used. This warm-up process is based on unitless machine settings, rather than actual temperatures, all of which have been optimised throughout the development process. Due to shifts in the infra-red sensors used to monitor the machine temperatures, it is common practice to optimise these settings manually in the SLS process, and the same process is currently being used in the HSS process. All warm-up settings were maintained constant for each of the builds carried out

In order to assess the effects of the bed temperature and infra-red lamp power, four separate builds of 6 tensile test specimens were produced, at low and high settings for each of the variables (105 and 109 for the part bed heater, and $1.4 \mathrm{~kW}$ and $1.6 \mathrm{~kW}$ for the lamp powers) were selected. The input power to the lamp had previously been measured using a TENMA 727221 clamp meter. These parameters were selected as being at the high and low ends of the range within which acceptable parts can currently be produced. The selection of these parameters for investigation was based on the SLS research discussed previously.

(Table 1 shows the machine parameters used for each build).

\begin{tabular}{|c|c|c|c|c|}
\hline $\begin{array}{c}\text { 'Warm up' } \\
\text { cycle settings }\end{array}$ & \multicolumn{3}{|c|}{ Operating cycle settings } \\
\hline All Builds & Build & Build & Build & Build \\
& No. 1 & No. 2 & No. 3 & No.4 \\
\hline
\end{tabular}




\begin{tabular}{|c|c|c|c|c|c|}
\hline $\begin{array}{c}\text { Left Feed Bed } \\
\text { (Overhead Heater) }\end{array}$ & 59 & \multicolumn{5}{|c|}{59} \\
\hline $\begin{array}{c}\text { Part Bed (Overhead } \\
\text { Heater) }\end{array}$ & 100 & 109 & 105 & 109 & 105 \\
\hline Infrared Lamp Power & OFF & $1.6 \mathrm{~kW}$ & $1.6 \mathrm{~kW}$ & $1.4 \mathrm{~kW}$ & $1.4 \mathrm{~kW}$ \\
\hline $\begin{array}{c}\text { Right Feed Bed } \\
\text { (Overhead Heater) }\end{array}$ & OFF & & \multicolumn{3}{|c|}{80} \\
\hline Piston Heater & 150 & & & \\
\hline Cylinder Heater & 130 & \multicolumn{3}{|c|}{130} \\
\hline
\end{tabular}

Table 1 - Machine parameters for each build

Once each build was complete, the machine was allowed to cool down overnight before the parts were removed from the chamber.

\section{Powder bed hardness testing}

Previous research into the HSS process indicated that the infra-red lamp power appeared to have an effect on the hardness of the unsintered powder, as a result of exposing the entire part bed to infra-red radiation ${ }^{4}$, although no investigation of part properties was performed during this work. An increase in the hardness of the unsintered powder could make part removal more difficult than for SLS. The hardness of the unsintered powder was therefore also recorded for each build. 
Once each build was complete, and the machine had been allowed to cool to room temperature, the hardness of 49 evenly spaced positions across the part bed surface was recorded (see Figure 4), using a Ridsdale hardness indentor ('B' scale of 0 - 100), commonly used for measuring the hardness of sand casting material. The measurements were taken according to a comparative scale from 1 to 100. Based on previous experience, areas with a hardness lower than 35 allow for easy part removal, whereas measurements of over 60 normally require some use of tools to remove the excess powder. The gentle use of a scalpel should not present a problem for many parts, but for particularly fine-featured components this could result in some part damage. This can also be a time-consuming and process, and will lead to additional labour costs for part production, which would be of particular concern when using HSS for manufacturing.

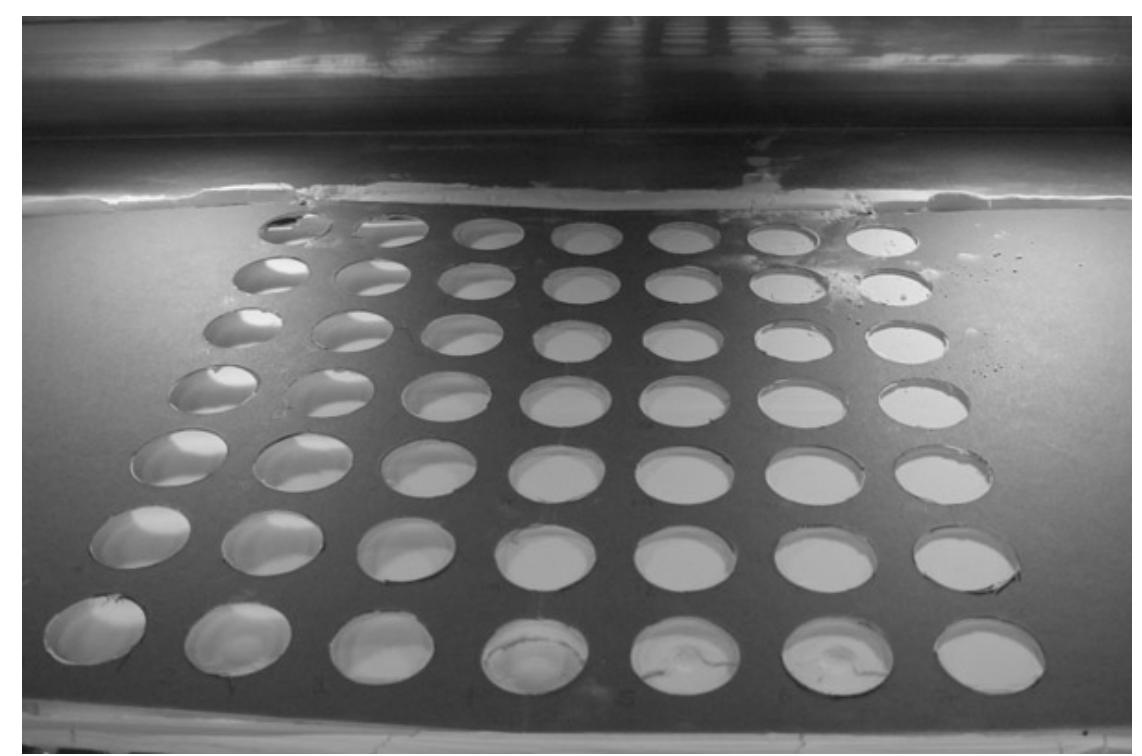

Figure 4 - Hardness measurement positions 


\section{Post-processing}

Once the hardness measurements had been taken, all parts were removed from the part cake and bead-blasted, in order to remove any excess powder. The specimens were then stored in a temperature controlled environment $\left(23^{\circ} \mathrm{C}+/-2^{\circ} \mathrm{C}\right)$ for at least 40 hours prior to carrying out tensile testing, in accordance with ASTM D638-96.

\section{Tensile Testing}

Tensile tests were performed on the specimens using a Zwick Z030 tensile testing machine fitted with an extensometer. The Zwick software, TestXpert, was used to enable the calculation of the tensile strength, Young's Modulus and elongation at break of each of the parts. The results shown in the following sections are based on the data from of all six specimens produced under each set of conditions.

\section{Results and Discussion}

\section{Part Properties}

Tensile Strength

Figure 5 shows the average and the range of values of Tensile Strength for each set of build parameters. 


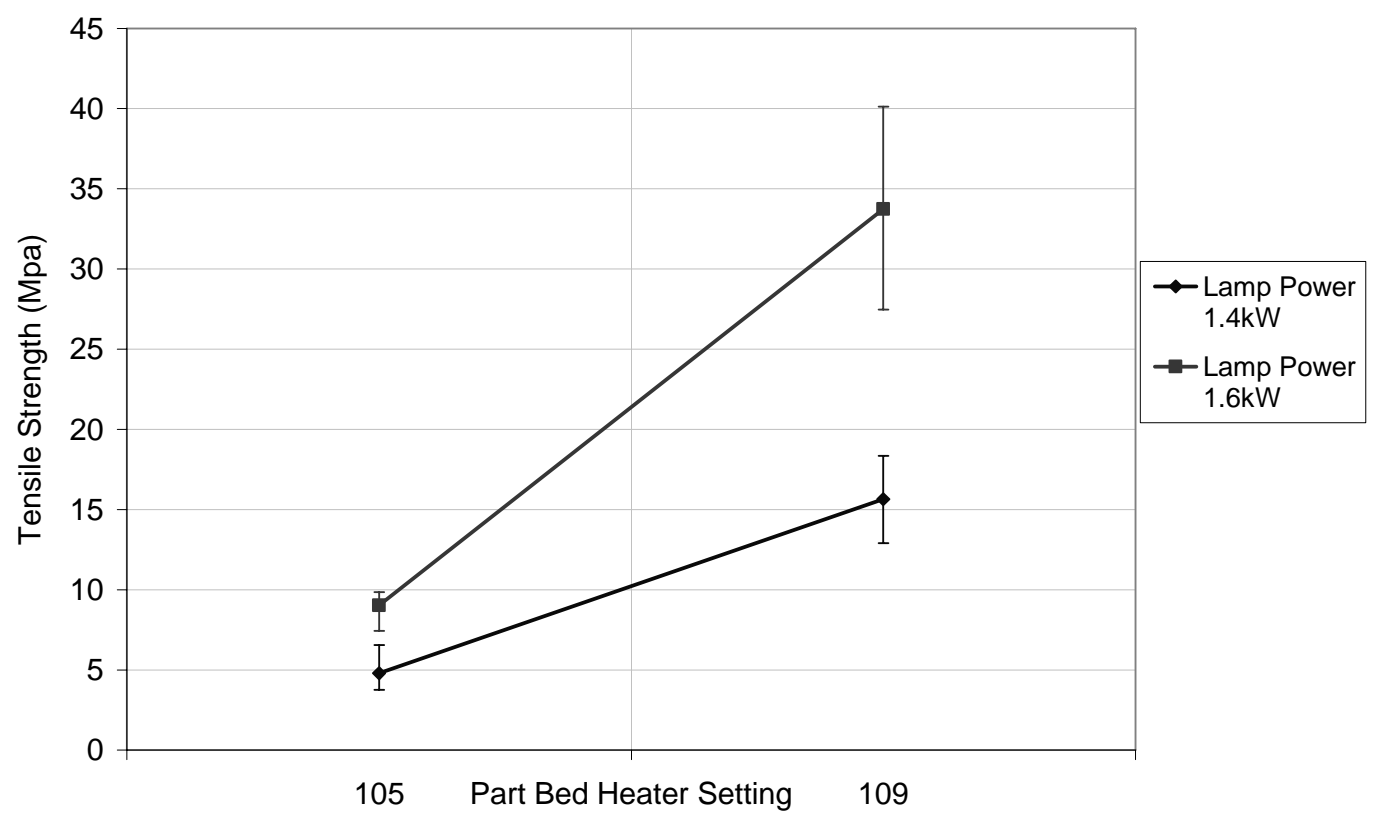

Figure 5 - Effect of part bed temperature and lamp power on tensile strength

It can be seen that an increase in the part bed temperature led to an increase in the average tensile strength of the parts. It can also be observed that the parts produced at the higher bed temperatures all possessed higher tensile strengths than those produced at the lower bed temperatures. An increase in the infra-red lamp power at either of the two part bed temperatures also corresponded to increased tensile strength. However, it is clear that, within the ranges tested, varying the bed temperature had a greater effect on the tensile strength than varying the lamp power.

It can also be seen from the gradients of the graphs shown in Figure 5 that the effect of varying the part bed temperature becomes greater at the higher infra-red lamp power. 
Whilst it is clear that higher properties are obtained at higher levels of the factors assessed, it can also be seen that the range of values (indicating the variation between part properties) for each build was substantially greater at the higher bed temperature.

Young's Modulus

Figure 6 shows the average and range of values of Young's Modulus for each set of build parameters.

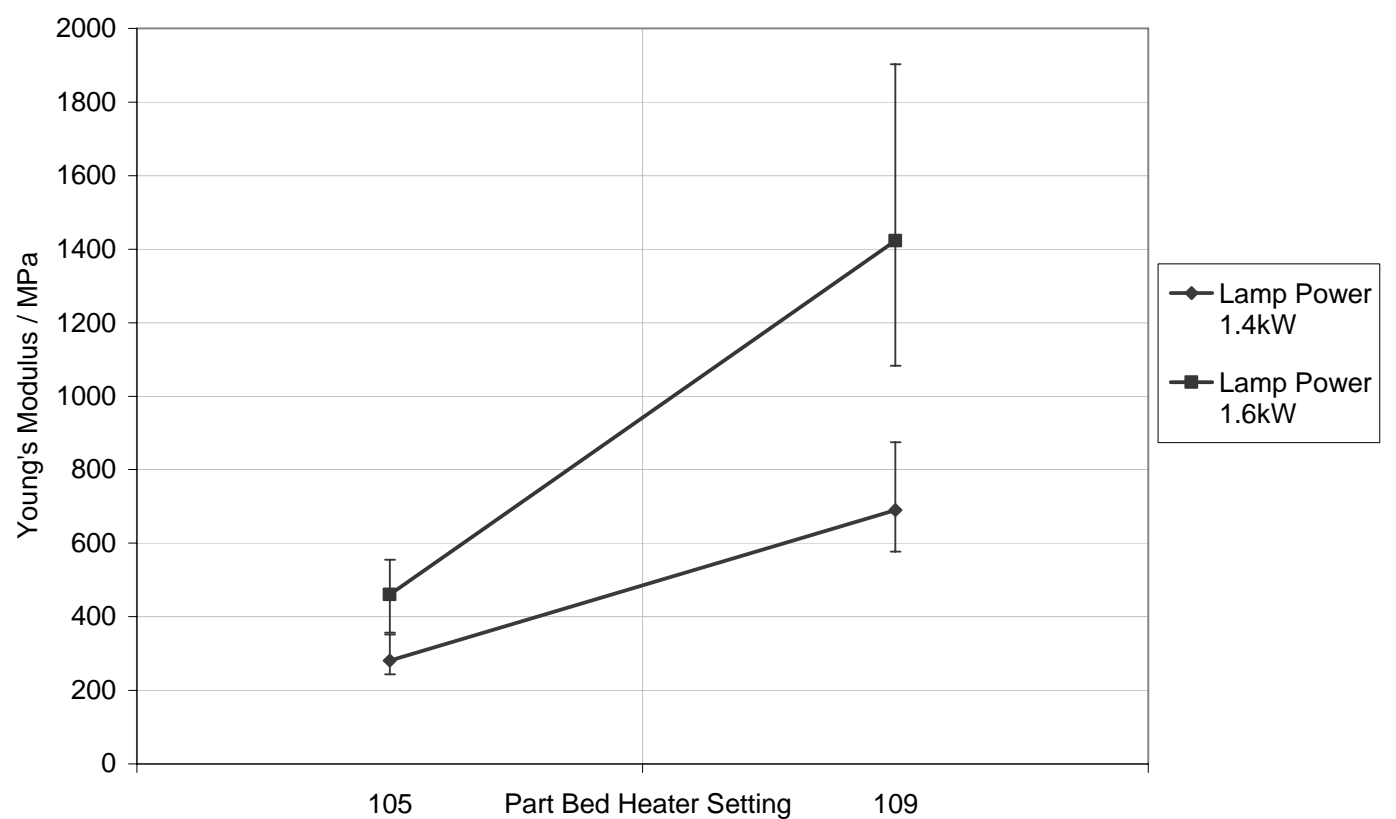

Figure 6 - Effect of part bed temperature and lamp power on Young's Modulus

As for the Tensile Strength, the Young's Modulus increased with an increase in bed temperature and/or lamp power, and the effect of increasing the bed temperature once again had the dominant effect. As before, the steeper 
gradient at the higher lamp power indicates that increases in bed temperature are more effective at the higher lamp power.

Once again, the range of values recorded at the higher bed temperature was greater than at the lower setting.

Elongation at Break

Figure 7 shows the average and range values of Elongation at Break for each set of build parameters.

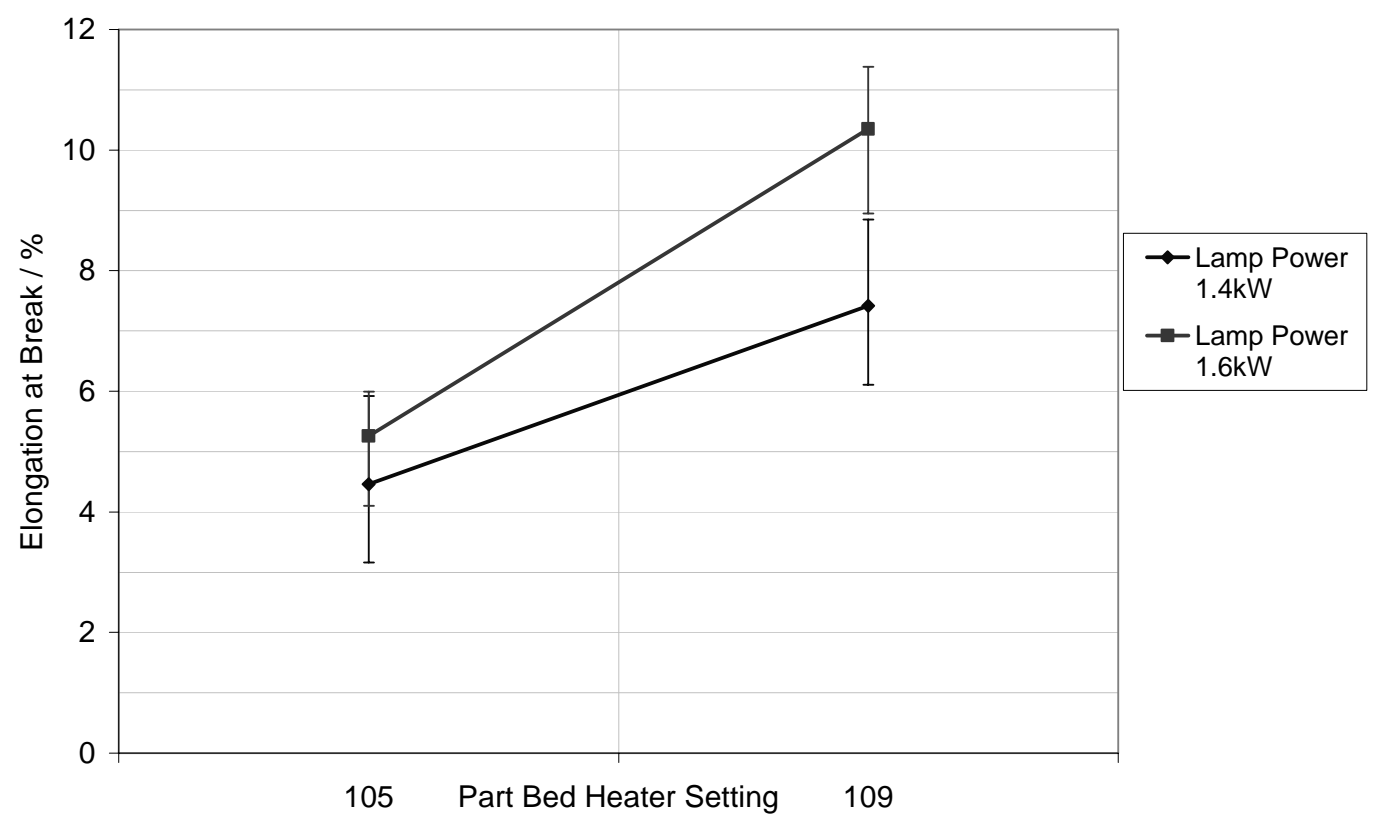

Figure 7 - Effect of part bed temperature and lamp power on elongation at break

It can be seen that the higher values of Elongation at Break were also obtained at the higher part bed temperature, but that an increase in the lamp power at either temperature also corresponded to an increase in the 
Elongation at Break. Once more, the gradient of the graph at the higher lamp power was greater than at the lower lamp power, indicating that a change in bed temperature has a greater effect at the higher lamp setting.

In this case, the range of values recorded was approximately the same under each of the build conditions tested.

\section{Summary}

These results indicate that the part bed temperature and the infra-red lamp power both have an influence on HSS part properties.

The results presented have shown that, for each mechanical property recorded, an increase in the bed temperature corresponded to an increase in the property. The same was true of the infra-red lamp power, although to a lesser extent than varying the bed temperature, within the range tested.

However, it has also been shown that the increase in part properties at the higher bed temperature corresponds to an increase in the variation in properties between parts. The ability to build parts with repeatable properties is especially important when considering Rapid Manufacturing requirements, and this variation in parts will also need to be reduced. 


\section{Powder Bed Hardness}

Figures 8 a to $d$ show the hardness values recorded on the dimensionless Ridsdale scale for the powder bed surface at the end of each build.

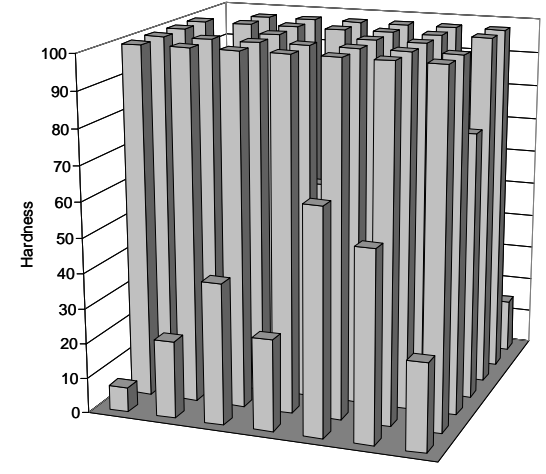

a. High Bed Temp, High Lamp Power

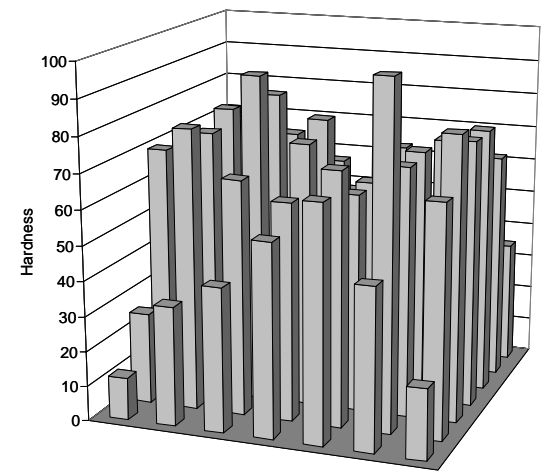

c. High Bed Temp, Low Lamp Power

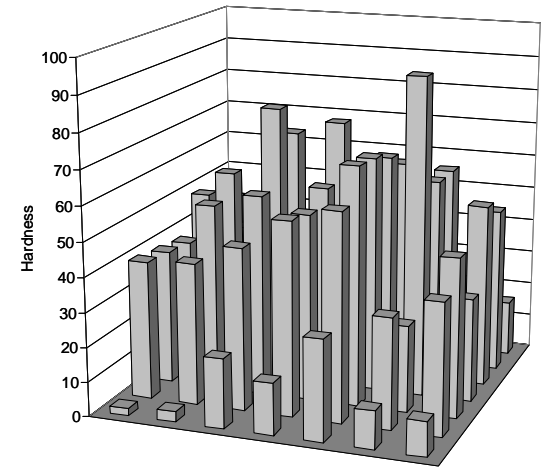

b. Low Bed Temp, High Lamp Power

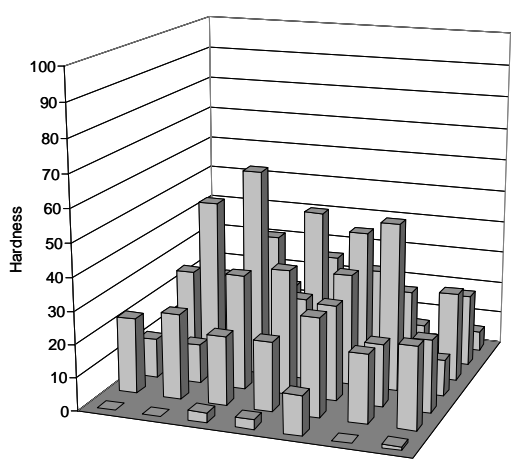

d. Low Bed Temp, Low Lamp Power

Figure 8 - Unsintered powder hardness values for each build

For all builds it can be seen that the highest levels of powder bed hardness could be found towards the centre of the part bed. As the centre of the bed is normally expected to be slightly warmer than the outsides, this increase in hardness towards the centre is as would be expected, assuming thermal causes have the dominant effect on the unsintered powder hardness. The 
areas in which parts were built also showed slightly higher hardness values, thought to be as a result of the parts built directly beneath them, at a distance of only $0.5 \mathrm{~mm}$.

As with the mechanical properties discussed in the previous section, an increase in either the part bed temperature or the infra-red lamp power led to an increase in the hardness of the unsintered powder.

It can be seen that, at the high level of both settings, the unsintered powder hardness over the entire bed was high enough (almost 100) to require the use of a scalpel or other tool to remove the unsintered powder from the part.

When the bed temperature was maintained at its high level, and the infra-red power level was reduced to the low level, the hardness in most areas as still hard enough to require some use of tools to remove the parts, although somewhat lower than for the high lamp power (an average of just under 70).

As the bed temperature was reduced but the lamp power increased to its high level, the powder hardness reduced to an average of approximately 50 , with some areas requiring the use of tools to remove the parts.

At the low level of both factors, most of the part bed fell below hardness levels where tooling was required, and parts could be removed relatively easily. 
Figure 9 shows the effect of each of the varied parameters on the average powder hardness at the bed surface.

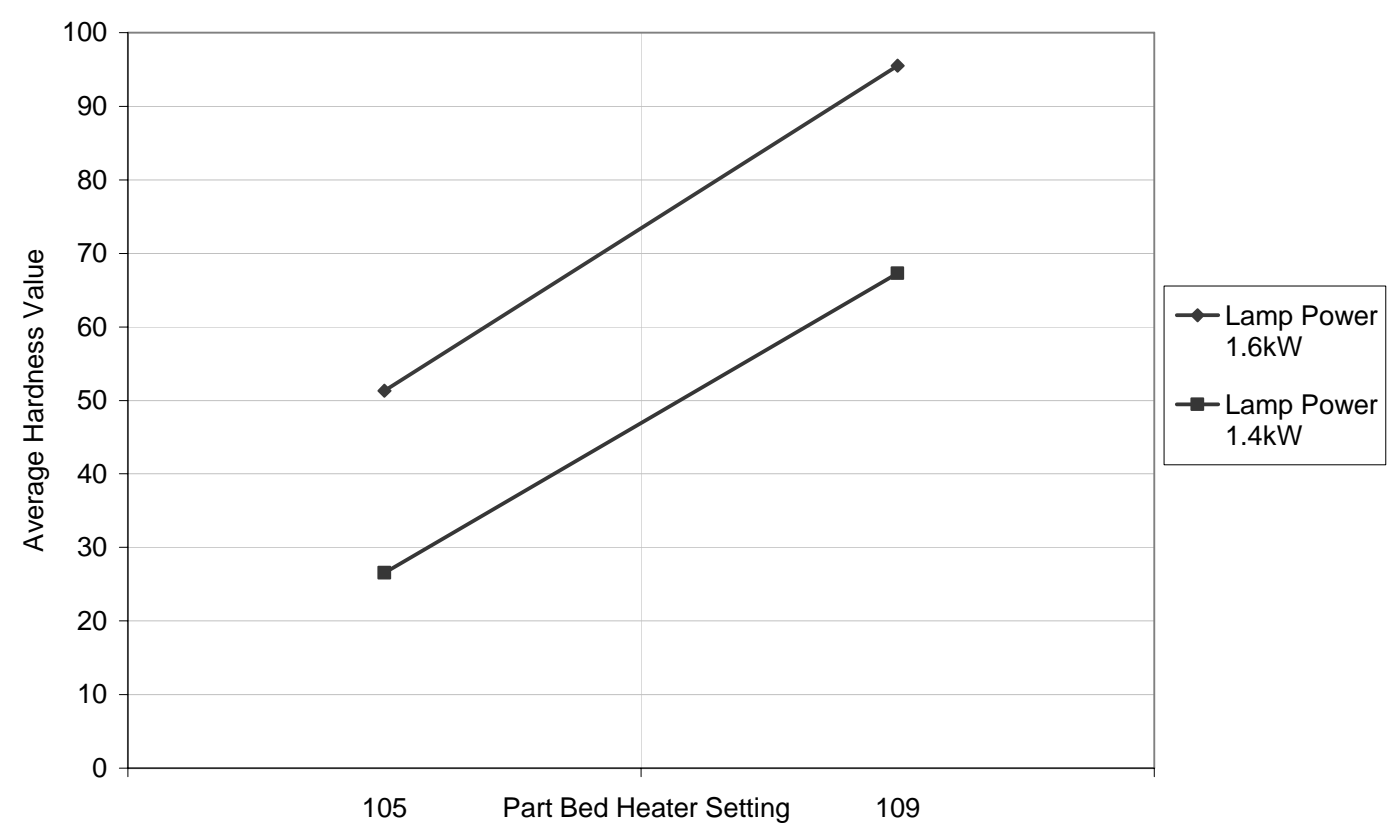

Figure 9 - Effect of part bed temperature and infra-red lamp power on unsintered powder hardness

It can be seen that both the part bed temperature and the infra-red lamp power had an effect on the powder bed hardness. This corresponds to the effects identified in the mechanical property results discussed previously. However, in this case it appears, from the gradients of the graph, that there is very little difference between the effect of varying either factor over the range tested, suggesting that both factors have the same impact on the powder hardness. 


\section{Further Discussion}

Table 2 ranks each of the measured properties in order of decreasing magnitude.

\begin{tabular}{|l|l|l|l|l|}
\hline \multicolumn{1}{|l|}{$\begin{array}{l}\text { Tensile } \\
\text { Strength (MPa) }\end{array}$} & $\begin{array}{l}\text { Elongation at } \\
\text { break (\%) }\end{array}$ & $\begin{array}{l}\text { Young's } \\
\text { Modulus (MPa) }\end{array}$ \\
\hline Build \# & Build \# & Build \# & Build \# \\
\hline Highest & 1 & 1 & 1 & 1 \\
\hline & 3 & 3 & 3 & 3 \\
\hline Lowest & 2 & 2 & 2 & 2 \\
\hline
\end{tabular}

Table 2 - Ranking of build vs. mechanical properties

It can be seen that each of the part properties and the hardness values measured demonstrated the same trend, with build one showing the highest value, followed by build 3 , build 2 , and finally build 4 possessing the lowest value for each property. This indicates that there is a trade-off between increasing the mechanical properties of the parts produced, and maintaining a low enough level of hardness, such that part removal is not affected.

When using variations in part bed temperature and infra-red lamp power to increase the mechanical properties of HSS parts, this can therefore be expected to lead to an increase in the hardness of the unsintered powder in the part bed. 


\section{Conclusions and Recommendations}

Results have shown that increasing the bed pre-heat temperature, and the infra-red lamp power, also lead to an increase in tensile strength, Young's Modulus, and elongation at break, although it can be expected that, beyond a certain point, further increases may lead to powder degradation and a decrease in the properties of sintered parts.

The increase in part properties at higher bed temperature and lamp power corresponds to an increase in the hardness of the unsintered powder, and therefore in the difficulty of part removal. The importance of this increased hardness will depend on the specific part geometry, but may in some cases result in damage to the parts during post-processing.

As the higher mechanical properties were found at the higher bed temperature, the results show that increasing the level of this should be the first step towards increasing the part properties. Once a higher bed temperature had been reached, an increase in the infra-red lamp power could be used in order to further increase the mechanical properties, if required. Whilst these conclusions can only be stated definitely within the ranges tested for each parameter, it should be remembered that these levels were specifically chosen as being at the low and high ends of the ranges within which parts can currently be produced, and therefore provide acceptable indications for the current state of the process. 


\section{References}

${ }^{1}$ Cooper K, Rapid Prototyping Technology: selection and application, Marcel Dekker, 2001

${ }^{2}$ Hopkinson, N., Hague, R.J.M. and Dickens, P.M., Rapid Manufacturing: an Industrial Revolution for the Digital Age, Chichester, West Sussex: John Wiley and Sons Ltd; 2005. ISBN 0-470-01613-2.

${ }^{3}$ Wohlers, T., Rapid prototyping Tooling and Manufacture Annual State of the Industry Report, Part 6: Rapid Manufacturing, Wohlers Associates, USA, 2006

${ }^{4}$ Hopkinson, N. and Erasenthiran, P.E., High Speed Sintering - Early research into a new Rapid Manufacturing process, Proceedings from the 15th SFF Symposium, Austin, Texas, August 2004, pp 312-320

5 Thomas, H.R., Hopkinson, N., and Erasenthiran, P.E., High Speed Sintering - Continuing research into a new Rapid Manufacturing process, Proceedings from the 17th SFF Symposium, Austin, Texas, August 2006

${ }^{6}$ Bingham, G., Hague, R., Tuck, C., Long, A., Crookston, J. and Sherburn, M., Rapid Manufactured Textiles, International Journal of Computer Integrated Manufacturing, Vol. 20, No. 1, $96-105,2007$

${ }^{7}$ Hague, R., Mansour, S., Saleh, N. and Harris, R., Materials analysis of stereolithography resins for use in Rapid Manufacturing, Journal of Materials Science 39 (2004) 2457 - 2464

${ }^{8}$ Hague, R., Mansour, S. and Saleh, N., Material and design considerations for Rapid Manufacturing, International Journal of Production Research 2004 vol. 42, no. 22, 4691-4708

${ }^{9}$ Ajoku, U., Hopkinson, N., Hague, R. and Erasenthiran, P., Investigating mechanical anisotropy and end-of-vector effect in laser-sintered nylon parts, Proc. IMechE Part B, Journal of Engineering Manufacture, 220, pp 1077 - 1086, 2006

${ }^{10}$ Caulfield, B., McHugh, P. and Lohfeld, S., Dependence of mechanical properties of polyamide components on build parameters in the SLS process, Journal of Materials Processing Technology, 182, pp $477-488,2007$

${ }^{11}$ Zarringhalam, H., Hopkinson, N.,Kamperman, N. and de Vlieger, J., Effects of processing on microstructure and properties of SLS Nylon 12, Materials Science and Engineering A, 435-436, 172-180, 2006

${ }^{12}$ Gibson, I., Shi, D. 'Material properties and fabrication parameters in selective laser sintering process', Rapid Prototyping Journal, 1997, 3(4):129-136

${ }^{13}$ Tontowi, A.E., Childs, T.H.C. 'Density prediction of crystalline polymer sintered parts at various power bed temperatures', Rapid Prototyping Journal, 2001, 7(3):180-184

${ }^{14}$ Hopkinson, N., Hague, R.J.M. and Dickens, P.M. Rapid Manufacturing and Industrial Revolution for the Digital Age .Chichester, West Sussex: John Wiley and Sons Ltd; 2005. ISBN 0-470-01613-2.

${ }^{15}$ Ho, H.C.H., Gibson, W.L., Cheung, W.L. 'Effects of energy density on morphology and properties of selective laser sintered polycarbonate', Journal of Materials Processing Technology, 89-90 (1999) 204-210

${ }^{16}$ ASTM D 638-96 'Standard Test Method for Tensile Properties of Plastics', ASTM International

${ }^{17}$ Gornet, T.J., Davis, K.R. 'SLS System Powder Management', Proceedings of the 3d Systems NASUG SLS User Group Joint Conference 2004.

April 25-29; Anaheim, California, USA. 2004. 